\title{
MARKETING STRATEGIES FOR HEALTH CARE SECTOR - EMERGING SCENARIO
}

\author{
M. Muniraju*, T.K. Srinath**
}

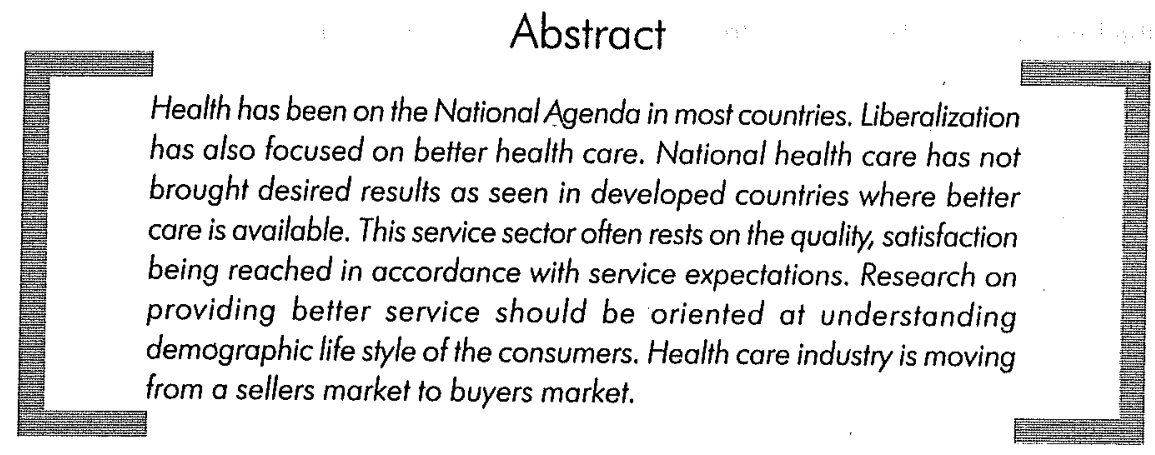

Liberalization and easy access to information has contributed to a general awareness about health, leading to identification of health care as a distinctive segment. However in a country like India, riddled with illiteracy \& poverty, where population exceeds 100 crores, majority of the people abstain from periodical checkup. Health services are preferred only when the problem worsens, though the equation in the end often results in concluding that cost of prevention is less than cost of curing.

National health policies in India are also reiterating on "Health For All" (HFA). These objectives, of course, are not fully materializing due to explosion in population, higher illiteracy rate as well as poverty.

* Sr. Lecturer, Department of Commerce, Bangalore University, Bangalore.

** Selection Grade Lecturer \& Research Scholar, M.L.A. College, Malleswaram 18th Cross, Bangalore - 560012. 
Into the foray of "Business", health care has been viewed as an important service providing center. Satisfaction through quality and protection through forum have been the important dimensions of this "business".

\section{Quality in Health Care}

Service providers are evaluated on their performance in satisfying needs and expectation. As the patient is ignorant of the technicalities of the services, they are incapable of evaluating medical care quality. Pricing is directly correlated to reputation of doctors, doctors often feeling price being a consequence of reputation.

In India, one of the disturbing and challenging realities of health care marketing is that - patients and other non-professional customers use their own criteria to select and judge service provider.

Health care prices are most often based on the cost to the provider rather than on demand by the consumer.

On the marketing mix front, concentration is more focussed on the core product, service being purchased mostly when inevitability is reached. Confidence and affordability are the key factors, which are often linked to price. Ignoring the key factors while deriving services of health care are resorted to only when such services are indispensable and when a higher risk is perceived.

Service Quality is often spread through word-of-mouth, reference group invariable playing major role. Specialized services are centrally located, while generalized ones are spread. Support systems exist but not well organized.

\section{STP in Health Care Marketing}

Segmentation, Targeting and Positioning should consider the aspects that mutually benefit the consumers and providers of service. Demographic and life style researches go a long way in effective segmentation. Physical environment in hospitals can play an important role in market segmentation, targeting and positioning and also better educated affluent patients and well-heeled segment look for VIP service. Physical environment in which services are produced and consumed generally provide an opportunity to tell the 'right story' about a given service. 


\section{Challenges Ahead}

Major reasons necessitating a shift towards marketing approach in India are:

- In certain market segments, competition is becoming more intense.

- More consumer awareness.

- Setting up of corporate hospitals

- Increasing purchasing power

- Need to attract limited available specialists.

Emphasis has to be placed on real effectiveness and performance. Performance and cost-effectiveness will define hospital quality. Service consumers of health care are more sophisticated, selective and value-oriented than ever before. It is essential for hospitals to embrace value marketing.

As quality is "zero defects - doing it right the first time" the hospitals should deviate from 'image building and advertising' to value system for patient i.e. service guarantees, educating patients, enhancing patient loyalty. Services need to be made easier to use, environmentally appealing and friendly.

Different segments of the general public use different sets of criteria when evaluating the quality of hospital health care and also the service characteristics of 'intangibility' and 'inseparability' stress the role of consumer in the delivery of service. Hospitals need to build 'relationships' with patients as quality is directly related to quantity of care and follow-up action.

Value can be achieved through a better-informed and knowledgeable patient. There is no substitute for 'getting it right the first time' and health provider should aim at reliability in value marketing. Consistent performance will do more for building service loyalty by patients than all of the added benefits combined.

The focus on health care is shifting from seller to buyer market. Commitment to quality must pervade the whole organization. In India, over- the counter (OTC) market for health care products is developing. The 'influencer' - friends, relatives and well wishers of the patient often provide the impetus to self-medication. The health care marketers should understand these changing trends before finalizing their strategies. 
Hospitals should aim at creating health care awareness rather than health care solutions. This exactly is the contribution of health care marketers to society - if followed in the coming years.

SEARCH is a Non Government Organization established with a focus of Human Resource Development in NGO sector in South Asia. In Indian development scenario SEARCH initiative began since 1975 with a consistent intervention for community development through capacitating actors committed for development cause Several organizational initiatives were evolved to create an impact. Niche area has been around promoting development professionals in the NGO sector in the realm of NGO management. Empowering women in Dharmapuri District, Tamil Nadu, where the organizational contribution is in promotion of Women's Empowerment, basically addressing $10 \mathrm{Key}$ Issues prevailing in the region (Karimangalm Block). A holistic view on empowerment is focused on economic empowerment. Institutionalizing development concepts by creating apex structures like the registering a finance company under the Company's Act of 1956 with an exemption under section 25 .

In the State of Karnataka, SEARCH has been involved in strengthening elected women representatives. Intervention at the grass roots of political process is almost a decade. Leveraging IT for development providing software support to NGO as well as providing IT solutions for better management Setting up an infrastructural base. The Search Human Resource Development center is enabling the various learning in dissemination to the sector. A scientific study and knowledge management of the several interventions is carried out by the Development Communication which has nearly 50 publications to its credit. 